\title{
BIOLOGIA FLORAL, SISTEMA REPRODUTIVO E MÉTODOS ARTIFICIAIS DE HIBRIDAÇÃO DE Hemerocallis hybrida
}

\author{
Floral biology, reproductive system and artificial methods of hybridization of Hemerocallis hybrida
}

\author{
Sara Pereira Menezes ${ }^{1}$, Antonio Carlos de Oliveira²
}

\begin{abstract}
RESUMO
A espécie ornamental Hemerocallis hybrida Hort. é uma planta herbácea perene originária da Ásia. Conduziu-se este trabalho, com o objetivo de estudar métodos artificiais de hibridação, biologia floral e o sistema reprodutivo de plantas de 'lírio-de-São-José', com vistas a gerar subsídios a programas de melhoramento genético dessa espécie ornamental. A técnica de cobertura do estigma de flores de 'lírio-de-São-José', ao invés de se cobrir toda a flor, após a realização do cruzamento artificial, proporciona maior taxa de pegamento e maturação de cápsulas de sementes ( $p<0,001$; Teste $\chi^{2}$ de contingência $2 x 2$; correção de Yates). A antese é a melhor fenofase para realização de cruzamentos controlados, apresentando taxa de receptividade estigmática de $100 \%$, sendo a quantidade de grãos de pólen viáveis $45 \%$ maior que na fase senescência. A espécie estudada é hermafrodita, sendo essencialmente alógama, apresentando índices de autoincompatibilidade e de autogamia iguais a zero.
\end{abstract}

Termos para indexação: Alogamia, planta ornamental, polinização.

\begin{abstract}
The ornamental species Hemerocallis hybrida Hort. is a perennial herbaceous plant originated in Asia. The objective of the present work to study the artificial methods of hybridization, floral biology and reproductive system of daylily plants to support genetic and breeding programs of this species. The technique of covering the stigma of daylily's flowers with aluminum paper instead of covering the whole flower after the artificial crossing, provides higher setting and maturation of seed capsules $\left(p<0,001\right.$; Test $\chi^{2}$ contingency 2 x 2; correction of Yates). Blooming is the best phenophase for controlled crossings with estigmatic reception of $100 \%$, and amount of viable pollen grains of $45 \%$ higher then the phase of the senescence. The studied species is hermaphrodite, essentially allogamous, with self-incompatibility and autogamy indexes equal to zero.
\end{abstract}

Index terms: Allogamy, ornamental plant, pollination.

(Recebido em 10 de agosto de 2009 e aprovado em 28 de julho de 2010)

\section{INTRODUÇÃO}

O 'lírio-de-São-José', também denominado de 'líriode-um-dia' (port.) e daylily (inglês) (Hemerocallis hybrida Hort.), pertencente a família Hemerocallidaceae, é uma planta ornamental asiática (Tombolato et al., 2004) cujo gênero possui 30 espécies (Grenfell, 1998), de amplo uso paisagísticos, culinário (Uezu, 1997) e medicinal indicado como: diurético, antitérmico (Yang et al., 2003), antioxidante (Zhang, 2004); inibidor de crescimento de células cancerígenas (Cichewicz et al., 2004) e da multiplicação do parasita Schistosoma mansoni (Cichewicz et al., 2002).

Entretanto, é como planta ornamental que é mais valorizada comercialmente em várias partes do mundo (Tomkins et al., 2001). As características mais apreciadas para o emprego do 'lírio-de-São-José' na floricultura são a diversidade de cores e formas de suas flores e grande adaptabilidade à diferentes condições climáticas (Munson Junior, 1989; Saito et al., 2003). Por muito tempo, o 'lírio-de-
São-José' foi considerado uma planta que não apresentava doenças que acarretassem prejuízos à sua estética (Saito et al., 2003). Porém, nos últimos anos, tem sido infectado ao ponto de comprometer a sua comercialização (Gatlin, 1999). Entre tais enfermidades, destaca-se a ferrugem causada pelo fungo Puccinia hemerocallidis Thüem (Williams-Woodward \& Buck, 2003), descrita no Estado de São Paulo em 2001 (Carvalho Júnior et al., 2001) e recentemente, também na Bahia (Menezes et al., 2008).

$\mathrm{O}$ agronegócio da floricultura brasileira tem crescido expressivamente nos últimos anos, principalmente em relação às exportações tendo alcançado de janeiro a setembro de 2008 um aumento de 6,1\% em comparação ao mesmo período do ano anterior (Kiyuna et al., 2005, 2008). Movimenta no mercado interno cerca de 750 milhões de dólares ao ano (Landgraf \& Paiva, 2009) A produção de híbridos que tenham características paisagísticas, fitotécnicas e de resistência a patógenos desejadas pelos floriculturistas e mercado consumidor é de grande interesse

1Universidade Estadual de Santa Cruz/UESC - Rodovia Ilhéus-Itabuna - Km 16 - 45662-000 - Ilhéus, BA - menezes_sp@yahoo.com.br ${ }^{2}$ Universidade Estadual do Sudoeste da Bahia/UESB - Departamento de Ciências Naturais - Vitória da Conquista, BA 
para a floricultura nacional. Para tanto, o conhecimento da biologia floral, do sistema reprodutivo e de métodos de hibridação são necessários (Ferreira et al., 2004). O sistema reprodutivo de uma espécie pode variar de acordo com as condições climáticas de uma região (Escobar et al., 1986; Oddie \& McComb, 1998) sendo responsável pela estrutura genética de uma população (Loveless \& Hamrick, 1984).

O 'lírio-de-São-José' é uma planta hermafrodita usada em hibridações inter e intra-específicas em várias partes do mundo, o que tem proporcionado o surgimento de uma grande variedade de plantas com diferentes cores e formas que contribuíram para a sua grande utilização em paisagismo (Tombolato et al., 2004). No entanto, na literatura científica as informações relativas aos aspectos de biologia floral e de polinização envolvidos na reprodução dessa espécie são restritas. Algumas informações mencionam ser uma espécie autoincompatível (Menezes \& Barros, 2001).

Neste trabalho, objetivou-se estudar a biologia floral e o sistema reprodutivo de plantas de 'lírio-de-SãoJosé' cultivadas nas condições edafo-climáticas de Vitória da Conquista - BA; com vistas a otimizar protocolos de hibridação para serem aplicados em programas de melhoramento genético desta espécie.

\section{MATERIAL E MÉTODOS}

Ensaio I - Comparação de métodos de hibridação artificial. Um conjunto de 55 flores, no final de pré-antese, foram emasculadas, ensacadas com papel vegetal semipermeável por 24 horas e polinizadas com a ajuda de pincéis, com grãos de pólen coletados de anteras de flores, na fase de pré-antese, armazenados por 24 horas em vasilhames plásticos. Após a polinização artificial, procedeu-se: o ( $i$ ) re-ensacamento de 27 flores e a (ii) cobertura da região do estigma com papel alumínio de 28 flores artificialmente polinizadas, até a ocorrência da senescência floral. O primeiro dos métodos testado é universalmente utilizado em polinização artificial de flores para se evitar polinização indesejada após hibridação artificial e a segunda estratégia é preconizada por cultivadores de lírio nos Estados Unidos sendo que, não há referência de ter sido avaliada experimentalmente.

As frequências de pegamento e maturação de cápsulas de sementes para $i$ e $i i$ foram submetidas ao Teste $\chi^{2}$ de contingência $2 \times 2$ (correção de Yates) e Teste Exato de Fisher, respectivamente (Zar, 1984). O pegamento foi considerado quando apareciam cápsulas de sementes 20 dias após a polinização indicando que houve fecundação. Ensaio II - Biologia floral. Dez botões florais por fenofase de pré-antese, antese e senescência foram coletados entre $09 \mathrm{~h} 00 \mathrm{~min}$ e $10 \mathrm{~h} 00 \mathrm{~min}$, haja vista que a antese da variedade 'lírio-de-São-José' nas condições edafoclimáticas da região onde foi realizado este estudo é essencialmente diurna, com vistas a realizar o $(i)$ teste de viabilidade polínica e o (ii) teste de receptividade do estigma. As anteras foram coletadas com auxílio de pinça, sendo a viabilidade polínica determinada por meio da coloração dos grãos de pólen com carmim acético a $2,5 \%$. Os grãos de pólen em cada uma das fenofases florais foram misturados com o carmim acético e contados em uma câmara de Neubayer (número total de grãos de pólen $/ \mathrm{mL}=\mathrm{n}^{\circ}$ de grãos de pólen $/ \mathrm{n}^{\circ}$ de quadrantes contados, multiplicado pelo valor da diluição, sendo o valor obtido multiplicado por $10^{4}$ ), por meio de observação em microscópio ótico, conforme Almeida (1986). A receptividade do estigma foi determinada em lupa de bancada pela observação de viscosidade presente na superfície do estigma, conforme Almeida (1986) e formação de bolhas ao se depositar peróxido de hidrogênio $\left(\mathrm{H}_{2} \mathrm{O}_{2}\right)$ a $3 \%$ sobre o estigma (Kearns \& Inouye, 1993). A avaliação constou da detecção de presença ou ausência de viscosidade e bolhas de ar na superfície do estigma.

Ensaio III - Sistema reprodutivo. Um lote de 600 botões florais foi aleatoriamente selecionado, estando todos em pré-antese e submetidos, 100 botões florais cada um, sempre entre $09 \mathrm{~h} 00 \mathrm{~min}$ e $10 \mathrm{~h} 00 \mathrm{~min}$, aos seguintes ensaios reprodutivos:

- Autopolinização artificial: os botões foram manualmente abertos; grãos de pólen da mesma flor foram depositados sobre o estigma da mesma. Em seguida, o estigma foi coberto com papel alumínio;

- Autopolinização natural: os botões foram ensacados com sacos de papel semipermeável, permanecendo ensacados por 12 horas;

- Polinização cruzada artificial: Os botões florais em pré-antese foram emasculados e sobre seus estigmas foram depositados grãos de pólen oriundo de flores de outras plantas. Após o cruzamento, o estigma foi isolado com papel alumínio;

- Polinização cruzada natural: as anteras dos botões em pré-antese foram removidas e os estigmas das mesmas foram mantidos descobertos;

- Agamospermia: botões florais foram abertos com o auxílio de uma tesoura, as anteras foram removidas e, em seguida, cobriu-se a região do estigma com papel alumínio para evitar a polinização cruzada;

- Ensaio-Controle: os botões foram mantidos em condições naturais, servindo de comparação para os resultados obtidos nos demais ensaios reprodutivos. 
Decorridos 150 dias, período necessário para finalização do ensaio III, avaliou-se as variáveis $(i)$ índice de autoincompatibilidade (IAI) com base na razão entre percentual de frutificação (i.e., obtenção de cápsulas de sementes) obtido no ensaio de autopolinização artificial e o percentual de frutificação obtido de polinização cruzada artificial e o (ii) índice de autogamia (IA), aferido como sendo a razão entre os percentuais de frutificação obtidos nos ensaios de autopolinização natural e o ensaio de polinização cruzada artificial. De acordo com Ruiz-Zapata \& Arroyo (1978), citados por Benezar \& Pessoni (2006) os valores de IAI e IA maiores que 0,2 indicam, respectivamente, a ocorrência de autocompatibilidade e autogamia como mecanismos reprodutivos recorrentes na espécie vegetal que está sendo estudada.

Os três ensaios acima listados foram realizados durante o período de dezembro de 2004 a maio de 2005, no Horto da Prefeitura Municipal de Vitória da Conquista/BA (HPMVC) (Lat $14^{\circ} 53^{\prime} \mathrm{S}$; Long 40 48' W) em diferentes áreas onde se encontram dispostas plantas das variedades 'By MySelf' e 'Peach Pinwheel', podendo existir híbridos oriundos destas variedades de 'lírio-de-São-José'. O município de Vitória da Conquista/BA está situado entre as coordenadas $40^{\circ} 50^{\prime} 19^{\prime}$ ', oeste e $14^{\circ} 50^{\prime}$ '53'" sul, a uma altitude de $923 \mathrm{~m}$. A região é caracterizada por possuir um clima tropical de altitude com temperatura média anual de $20,2^{\circ} \mathrm{C}$, sendo a média das mínimas de $16^{\circ} \mathrm{C}$ e das máximas de $26^{\circ} \mathrm{C}$. A cidade registra precipitação pluvial anual de aproximadamente $700 \mathrm{~mm}$ (Murta et al., 2005; Lopes et al., 2010).

\section{RESULTADOS E DISCUSSÃO}

Comparação de métodos de hibridação artificial. As flores que foram submetidas à cobertura somente do estigma apresentaram taxa de pegamento de cápsulas de sementes $(64,3 \%)$ estatisticamente maior do que a apresentada por aquelas flores completamente reensacadas $(7,4 \%)\left(p<0,001\right.$; Teste $\chi^{2}$ de contingência $2 \times 2$; correção de Yates) (Tabela 1). A taxa de pegamento de cápsulas de sementes de 'lírio-de-São-José' aumentou em $768 \%(64,3 \% / 7,4 \%)$, ao se empregar o método de cobertura do estigma com papel alumínio, em relação ao método de re-ensacamento completo da flor.

Apesar de ser um procedimento corriqueiro em programas de melhoramento genético, o emprego de reensacamento de flores de 'lírio-de-São-José' apresenta inconvenientes como, por exemplo, o aumento da umidade no interior do saco, o que pode levar à baixa manutenção da fixação da flor na haste da planta. Por outro lado, o método de cobertura do estigma da flor com papel alumínio não acarreta essa desvantagem, além de permitir com que uma maior quantidade de grãos de pólen depositados sobre o estigma permaneça sobre o mesmo por um maior período de tempo aumentando, consequentemente, a probabilidade de fecundação dos óvulos e, consequentemente, formação de sementes.

Constatou-se que a eficiência do método de reensacamento da flor apresentou taxa de maturação $(83,3 \%)$ estatisticamente similar à obtida por meio da cobertura do estigma (100\%) ( $p=0,71$; Teste Exato de Fisher) (Tabela 1). Vale ressaltar que a baixa eficiência da maturação das cápsulas de sementes (16\%), obtida com o método de cobertura do estigma com papel alumínio, pode ser decorrente do elevado grau de parentesco entre as plantas utilizadas no experimento, já que no HPMVC a maior parte das plantas é resultante de propagação vegetativa de poucos genótipos ali instalados. Biologia floral. Quanto aos testes de receptividade do estigma, detectaram-se taxas diferenciais de receptividade do estigma de $20 \%$, para a fenofase pré-antese, $100 \%$ para a fenofase antese e de $20 \%$ para a fenofase de senescência floral. Com o emprego do peróxido de hidrogênio, detectou-se receptividade do estigma em 100\% em todas as três fenofases. A quantidade de bolhas de ar formada pela ação da deposição de peróxido de hidrogênio sobre o estigma foi, contudo, diferente entre as três fenofases, sendo muito maior para a antese e menor para as demais. Pode-se concluir, portanto, que a melhor fenofase para a realização de cruzamentos é a da antese. Semelhantemente ao descrito por Almeida et al. (2004), o teste de receptividade do estigma que explora a atividade da catalase é mais eficiente do que o teste de viscosidade da superfície do estigma, haja vista que sinaliza com maior

Tabela 1 - Frequências de pegamento e maturação de cápsulas de sementes de 'lírio-de-São-José' (H. hybrida Hort) de flores re-ensacadas e com o estigma coberto após a polinização artificial. (Vitória da Conquista/BA, dezembro/2004).

\begin{tabular}{ccccc}
\hline Métodos & Flores fecundadas & $\begin{array}{c}\text { Flores não } \\
\text { fecundadas }\end{array}$ & $\begin{array}{c}\text { Cápsulas com } \\
\text { sementes maduras }\end{array}$ & $\begin{array}{c}\text { Cápsulas } \\
\text { abortadas }\end{array}$ \\
\hline Cobertura do estigma & 18 & 10 & 3 & 15 \\
Re-ensacamento floral & 2 & 25 & 0 & 2 \\
Total & 20 & 35 & 3 & 17 \\
\hline
\end{tabular}


precocidade, do que o método oposto, se o estigma já se encontra receptivo para polinizações controladas.

Em relação aos testes de viabilidade polínica, os grãos considerados como viáveis apresentaram coloração vermelho-intenso, enquanto os grãos inviáveis apresentam coloração azul-claro. Observa-se que à medida que avançam os estádios fenológicos florais, ocorre uma diminuição da viabilidade do pólen entre as fenofases préantese, antese e senescência (de $98166 \pm 61543$ à $45000 \pm$ 21360) e aumenta a quantidade de grãos de pólen inviáveis $(2500 \pm 4330$ à $32500 \pm 56291)$ (Figura 1). Com isso, as fenofases antese e, sobretudo, a de pré-antese; são as melhores para se coletar pólen de anteras com vistas a se efetuar posteriores cruzamentos controlados, sendo a quantidade de grãos de pólen viáveis aproximadamente $45 \%$ e 55\% maior que na fase de senescência, respectivamente.

Cumpre salientar a limitação dos métodos de viabilidade polínica baseado na coloração citoquímica. Nesses casos, o corante realça o revestimento do grão corando somente pólens viáveis. Para grãos de pólen que possuem paredes espessas, o corante pode não penetrar acarretando em uma classificação errônea. Não há descrição de um corante universalmente indicado para determinar a viabilidade de pólens (Techio et al., 2006). No entanto, o carmim acético é um dos corantes mais empregados apresentando eficácia na estimativa da viabilidade.

Sistema reprodutivo. Os resultados de ensaios que simulavam experimentalmente diferentes sistemas reprodutivos vegetais em plantas de 'lírio-de-São-José' são apresentados na Tabela 2.

A avaliação dos resultados sugere que a espécie é autoincompatível, havendo formação de frutos maduros somente nos ensaios em que ocorrera a possibilidade de polinização cruzada (ensaio-controle, polinizações cruzadas artificial e natural). Observa-se que os maiores valores de sucesso reprodutivo e de formação de frutos foram obtidos com polinização cruzada artificial com percentual de $66 \%$ e $38 \%$, respectivamente (Tabela 2). A espécie se mostrou altamente incompatível (IAI = zero). O IA, aferido como igual a zero, indica que o 'lírio-de-São-José' apresenta um sistema reprodutivo preferencialmente alógamo. A xenogamia, nível de alogamia que uma espécie vegetal apresenta em uma dada localização geográfica onde é cultivada, foi registrada no intervalo de $60-70 \%$, podendo ser considerada de intensidade mediana à elevada.

O não pegamento de frutos e nem mesmo a ocorrência de desenvolvimento inicial de ovários nos ensaios reprodutivos de autopolinização natural e agamospermia suportam a hipótese de que 'lírio-de-SãoJosé' tem porcentagem baixa ou nula de autogamia natural e que a formação de sementes apomíticas no interior de cápsulas de $H$. hybrida é improvável. No entanto, não é possível determinar se há ocorrência de apomixia facultativa, o que requer análises mais detalhadas de progênies, empregando técnicas avançadas como o uso de marcadores moleculares (Cavalli, 2003).

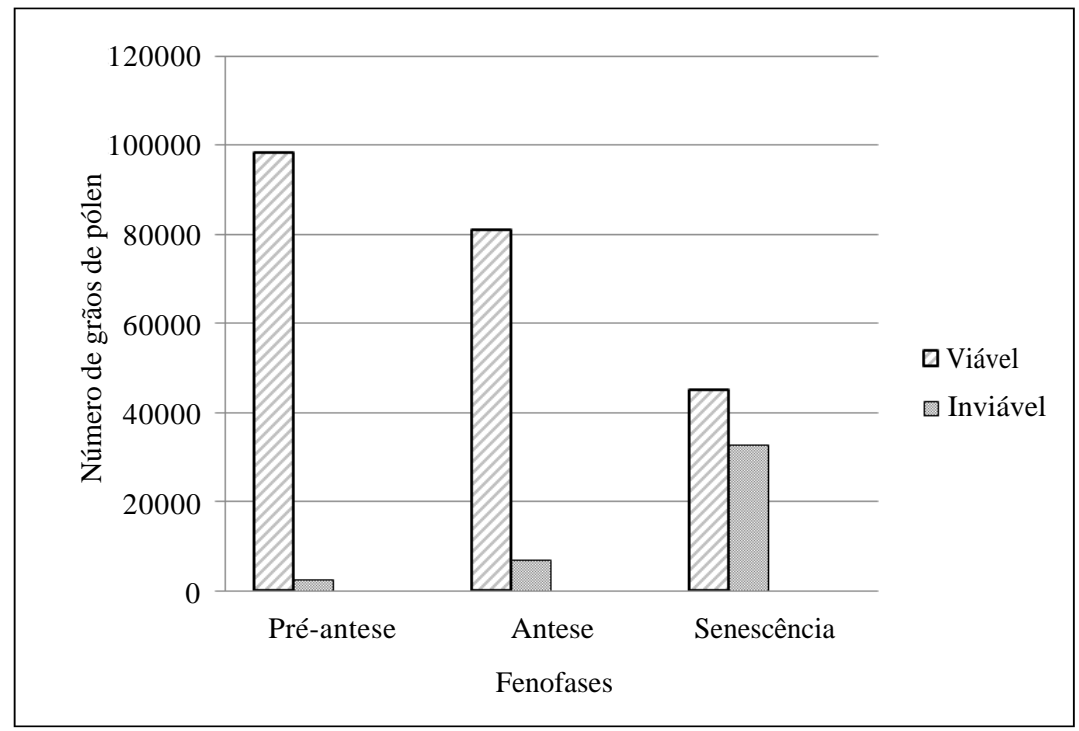

Figura 1 - Contagem do número de grãos de pólen viáveis e inviáveis das fenofases pré-antese, antese e senescência de flores de 'lírio-de-São-José' (Vitória da Conquista/BA, janeiro/2005). 
Tabela 2 - Avaliação de sistemas reprodutivos em plantas de 'lírio-de-São-José' (Vitória da Conquista/BA, dezembro/ 2004 a abril/2005).

\begin{tabular}{|c|c|c|c|c|c|}
\hline $\begin{array}{c}\text { Sistema Reprodutivo } \\
\text { Avaliado }\end{array}$ & $\begin{array}{l}\text { Número total de } \\
\text { flores avaliadas }\end{array}$ & $\begin{array}{l}\text { Número total de } \\
\text { cápsulas de } \\
\text { sementes pegas }^{(1)}\end{array}$ & $\begin{array}{c}\text { Sucesso } \\
\text { Reprodutivo }\end{array}$ & $\begin{array}{c}\text { Número total de } \\
\text { cápsulas de sementes } \\
\text { maduras }^{(2)}\end{array}$ & $\begin{array}{c}\text { Número de } \\
\text { sementes } \\
\text { obtidas }\end{array}$ \\
\hline $\begin{array}{l}\text { Autopolinização } \\
\text { artificial }\end{array}$ & 100 & 40 & $40 \%$ & 0 & 0 \\
\hline $\begin{array}{c}\text { Autopolinização } \\
\text { natural }\end{array}$ & 100 & 0 & $0 \%$ & 0 & 0 \\
\hline $\begin{array}{c}\text { Polinização cruzada } \\
\text { artificial }\end{array}$ & 100 & 66 & $66 \%$ & 38 & 615 \\
\hline $\begin{array}{c}\text { Polinização cruzada } \\
\text { natural }\end{array}$ & 100 & 4 & $4 \%$ & 1 & 11 \\
\hline Agamospermia & 100 & 0 & $0 \%$ & 0 & 0 \\
\hline Ensaio-Controle & 100 & 17 & $17 \%$ & 6 & 25 \\
\hline
\end{tabular}

Obs.: (1)O pegamento de cápsulas de sementes se caracterizava quando os mesmos despontavam nos receptáculos florais ainda imaturos. ${ }^{(2)} \mathrm{O}$ amadurecimento das cápsulas de sementes se caracterizava quando os mesmos apresentavam-se escurecidos e com a casca aberta.

A diferença do sucesso reprodutivo entre os ensaios de polinização cruzada artificial $(66 \%)$ e natural $(4 \%)$ pode ser interpretada no âmbito técnico, já que, para o primeiro tipo de ensaio reprodutivo, logo após a deposição de pólen sobre o estigma, o mesmo era envolvido com papel alumínio. Por sua vez, para as flores pertencentes ao ensaio de polinização cruzada natural, as anteras foram removidas, ficando totalmente sujeitas aos agentes naturais de polinização. É presumível supor que a técnica de cobertura do estigma assegure uma maior disponibilidade de pólen para formação de tubos polínicos o que, por conseguinte, resulta maior fecundação de gametas femininos e, consequentemente, maior taxa de pegamento de cápsulas e de obtenção de sementes. A baixa porcentagem de cápsulas de sementes obtidas no ensaio-controle (17\%) em relação ao ensaio de polinização cruzada artificial (66\%), também pode ser explicado pelo uso da cobertura do estigma com papel alumínio. No ensaio controle os botões florais funcionais abriram em condições naturais e estavam aptos a fazerem auto-fecundação e/ou fecundação cruzada estando, portanto, sujeitos à ação de agentes polinizadores e intempéries ambientais.

Outro fator que pode estar associado ao baixo sucesso reprodutivo nos ensaios envolvendo condições naturais é a relativa baixa presença de agentes polinizadores, uma vez que o HPMVC situa-se na zona urbana do município de Vitória da Conquista. Cumpre ainda ressaltar que foram coletados e identificados, nessa área, visitando flores do 'lírio-de-São-José', abelhas Apis mellifera e Trigona spinipes.
Mesmo sob condições técnicas idênticas (deposição de pólen no estigma seguida de cobertura do mesmo com papel alumínio) a porcentagem de sucesso reprodutivo da polinização cruzada artificial $(66 \%)$ foi estatisticamente maior do que a do ensaio de autopolinização artificial $(40 \%)\left(p<0,001\right.$; Teste $\chi^{2}$ de contingência $2 \times 2$ ). $\mathrm{O}$ aumento da taxa de pegamento das cápsulas de sementes com o sistema de polinização cruzada artificial foi de $65 \%$ (66\%/40\%). Apesar de a autopolinização artificial ter apresentado um sucesso reprodutivo relativamente alto, apresentando taxa de $40 \%$, não foi verificada a maturação de cápsulas de sementes provenientes do respectivo ensaio. A não maturação das cápsulas de sementes do ensaio de autopolinização artificial indica, possivelmente, a ocorrência de aborto em decorrência de processos de incompatibilidade tardia no sistema de fecundação. Aborto durante a formação de cápsulas de sementes de 'lírio-de-São-José' também fora observado por Menezes \& Barros (2001). Incompatibilidade é comum em várias espécies hermafroditas e pode ocorrer pela não germinação de grãos de pólen, a não fecundação de óvulos por grãos de pólen germinados ou porque grãos de pólen germinados não conseguem alcançar os óvulos (Pinto, 1995). Estes resultados confirmam a prevalência do sistema reprodutivo alógamo por plantas de 'lírio-de-São-José'.

A avaliação do sistema reprodutivo de variedade amarela de $H$. hybrida fora anteriormente descrita para as condições edafo-climáticas de Brasília/DF por Menezes \& 
Barros (2001). Com exceção do ensaio reprodutivo da 'polinização cruzada natural', os demais sistemas reprodutivos avaliados no presente trabalho foram também investigados por aquelas autoras. Três dos cinco ensaios reprodutivos (autopolinização natural, polinização cruzada artificial e agamospermia) avaliados pelo presente trabalho e descritos também por Menezes \& Barros (2001) apresentaram valores percentuais idênticos de sucesso reprodutivo $(0 \%, 66 \%$ e $0 \%$, respectivamente), o que corrobora a hipótese da ocorrência de autoincompatibilidade e de reprodução alógama no 'lírio-deSão-José'. Por sua vez, os valores percentuais do sucesso reprodutivo dos ensaios de 'autopolinização artificial' e do 'ensaio controle', obtidos no presente trabalho, $40 \%$ e $17 \%$, respectivamente, divergiram daqueles relatados por Menezes \& Barros (2001) (8\% e 44\%, respectivamente). Em relação ao ensaio de autopolinização artificial a diferença observada pode ser pelo emprego da cobertura do estigma com papel alumínio neste trabalho, face ao método de cobertura da flor com papel semipermeável, utilizado por aquelas autoras. Por sua vez, as condições ambientais e a baixa visitação de agentes polinizadores em Vitória da Conquista podem ter influenciado a menor obtenção de cápsulas de sementes no ensaio controle, em relação ao apurado experimentalmente em Brasília.

\section{CONCLUSÕES}

As análises dos resultados permitem indicar a cobertura do estigma de flores de 'lírio-de-São-José' como tratamento mais eficiente para geração de híbridos dessa espécie, pois proporcionou aumento da taxa de pegamento de cápsulas de sementes. $\mathrm{Na}$ antese estigmas encontram-se receptivos e grãos de pólen viáveis, constituindo a melhor fenofase para realização de cruzamentos. A espécie é autoincompatível tendo um sistema reprodutivo essencialmente alógamo. As informações geradas nesse trabalho poderão ser úteis em programas de melhoramento genético dessa planta ornamental.

\section{AGRADECIMENTOS}

Ao $\mathrm{CNPq}$ pela concessão da bolsa de iniciação científica (Proc. $n^{\circ}$ 104789/2004-2); à Enga ${ }^{\mathrm{a}}$. Agr ${ }^{\mathrm{a}}$. e Paisagista Luzia Lúcia Vieira de Silveira, coordenadora do Horto da Prefeitura Municipal de Vitória da Conquista/ BA, pela concessão da área experimental, juntamente com as mudas das plantas utilizadas neste experimento. Ao Prof. Dr. Cláudio Lúcio F. Amaral (DCB/UESB, Jequié/ BA), pelas sugestões por ocasião da instalação inicial dos ensaios.

\section{REFERÊNCIAS BIBLIOGRÁFICAS}

ALMEIDA, E.C. Biologia floral e mecanismos de reprodução em Crotaria mucrota. Revista Ceres, Viçosa, v.33, n.190, p.528-540, 1986.

ALMEIDA, O.S.; SILVA, A.H.B.; SILVA, A.B.; SILVA, A.B.; AMARAL, C.L.F. Estudo da biologia floral e mecanismos reprodutivos do alfavacão (Ocimum officinalis $L$.) visando o melhoramento genético. Acta Scientiarum - Biological Sciences, Maringá, v.26, n.3, p.343-348, 2004.

BENEZAR, R.M.C.; PESSONI, L.A. Biologia floral e sistema reprodutivo de Byrsonima coccolobifolia (Kunth) em uma savana amazônica. Acta Amazônica, Manaus, v.36, n.2, p.159-168, 2006.

CARVALHO JÚNIOR, A.A.; COUTINHO, L.N.; FIGUEIREDO, M.B. A primeira constatação da ferrugem do lírio-de-São José nas Américas. In: REUNIÃO ANUAL DO INSTITUTO BIOLÓGICO, 14., 2001, São Paulo. Arquivos do Instituto Biológico, São Paulo, v.68, p.57, 2001. Suplemento. CD-ROM.

CAVALLI, S.S. Apomixia: um método de reprodução assexual. In: FREITAS, L.B.; BERED, F. (Org.). Genética \& evolução vegetal. Porto Alegre: UFRGS, 2003. cap.3, p.41-55.

CICHEWICZ, R.H.; LIM, K.; MCKERROWB, J.H.; NAIR, M.G. Kwanzoquinones A-G and other constituents of Hemerocallis fulva 'Kwanzo' roots and their activity against the human pathogenic trematode Schistosoma mansoni. Tetrahedron, v.58, p.8597-8606, 2002.

CICHEWICZ, R.H.; ZHANG, Y.; SEERAM, N.P.; NAIR, M.G. Inhibition of human tumor cell proliferation by novel anthraquinones from daylilies. Life Sciences, v.74, p.1791-1799, 2004.

ESCOBAR, W.T.; ZARATE, R.D.R.; BASTIDAS, A. Biologia floral y polinizacion artificial del guanabano Annona muricata L. em condiciones del Valle del Caca, Colombia. Acta Agronomica, v.36, n.1, p.7-20, 1986.

FERREIRA, M.A.J.F.; QUEIROZ, M.A.; VENCOVSKY, R.; BRAZ, L.T.; VIEIRA, M.L.C. Implicações da expressão sexual e do sistema reprodutivo de melancia em programas de pré-melhoramento. Boletim de pesquisa e desenvolvimento/Embrapa Recursos Genéticos e Biotecnologia, Brasília, v.65, p.9-24, 2004. 
GATLIN, F.L. An illustrated guide to daylilies. 2.ed. Kansas City: The American Hemerocallis Society, 1999.

GRENFELL, D. The gardener's guide to growing daylilies. Portland: Timber, 1998.

KEARNS, C.A.; INOUYE, D.W. Techinques for pollination biologists. Niwot: University Press of Colorado, 1993.

KIYUNA, I.; ÂNGELO, J.A.; COELHO, P.J. Flores: perspectivas no mercado externo. Agroanalysis Revista de Agronegócio da Fundação Getúlio Vargas, São Paulo, v.25, p.26-27, 2005.

KIYUNA, I.; ÂNGELO, J.A.; COELHO, P.J. Floricultura: o difícil caminho do mercado externo. Análises e

Indicadores do Agronegócio, São Paulo, v.3, n.11, nov. 2008. Disponível em: <http://www.iea.sp.gov.br/outh verTexto.php?codTexto=9652>. Acesso em: 30 jan. 2008.

LANDGRAF, P.R.C.; PAIVA, P.D.O. Produção de flores cortadas no estado de Minas Gerais. Ciência e Agrotecnologia, Lavras, v.33, n.1, p.120-126, jan./fev. 2009.

LOPES, A.C.; VIANA, A.E.S.; MATSOMOTO, A.N.; CARDOSO JÚNIOR, N.S.; SÃO JOSÉ, A.R. Complementação da irrigação e épocas de colheita de mandioca cv. coqueiro no Planalto de Conquista, BA. Ciência e Agrotecnologia, Lavras, v.34, n.3, p.579-587, maio/jun. 2010.

LOVELESS, M.D.; HAMRICK, J.L. Ecological determinants of genetic structure in plant populations. Annual Review of Ecology and Systematics, Palo Alto, v.15, p.65-95, 1984.

MENEZES, N.S.; BARROS, M.A.G. Estudo da biologia floral de Hemerocallis hybrida. In: CONGRESSO DE INICIAÇÃO CIENTÍFICA DA UNIVERSIDADE DE BRASÍlLIA, 7., 2001, Brasília. Anais... Brasília: UnB, 2001. p.66.

MENEZES, S.P.; SOUZA, T.P.; SANTOS, A.; NOVAES, Q.S.; TAVARES, G.M.; JUNGHANS, D.T.; OLIVEIRA, A.C. Ocorrência da ferrugem do 'lírio-de-São-José causada por Puccinia hemerocallidis no Estado da Bahia. Magistra, Cruz das Almas, v.20, n.4, p.403-405, out./dez. 2008.

MUNSON JUNIOR, R.W. Hemerocallis, the daylily. Portland: Timber, 1989. 144p.
MURTA, R.M.; TEODORO, S.M.; BONOMO, P.; CHAVES, M.A. Precipitação pluvial mensal em níveis de probabilidade pela distribuição gama para duas localidades do Sudoeste da Bahia. Ciência e Agrotecnologica, Lavras, v.29, n.5, p.988-994, 2005.

ODDIE, R.L.A.; MCCOMB, J.A. Stigma receptivity in Eucalyptus camaldulensis Dehnh. Silvae Genetica, Frankfurt, v.47, n.2/3, p.142-146, 1998.

RUIZ-ZAPATA, T.; ARROYO, M.T.K. Plant reproductive ecology of a secundary deciduous tropical forest in Venezuela. Biotropica, v.10, n.3, p.221-230, 1978.

TECHIO, V.H.; DAVIDE, L.C.; PEDROZO, C.A.; PEREIRA, A.V. Viabilidade do grão de pólen de acessos de capim-elefante, milheto e híbridos interespecíficos (capim-elefante x milheto). Acta Scientiarum Biological Sciences, Maringá, v.28, n.1, p.7-12, 2006.

TOMBOLATO, A.F.C.; MATTHES, L.A.F.; BRANCO, A.M.M.; BERGEMANN, D. Hemerocale: Hemerocallis hybrida. In: TOMBOLATO, A.F.C. Cultivo comercial de plantas ornamentais. Campinas: Instituto Agronômico, 2004. p.172-210.

TOMKINS, J.P.; WOOD, T.C.; BARNES, L.S.; WESTMAN, A.; WING, R.A. Evaluation of genetic variation in daylily (Hemerocallis spp.) using AFLP markers. Theoretical and Applied Genetics, Heidelberg, v.102, p.489-496, 2001.

UEZU, E. A philological and experimental investigation of the effects of Hemerocallis as food in man and ddy mice. Bulletin of College of Education, University of the Ryukyus, v.51, p.231-238, 1997.

WILLIAMS-WOODWARD, J.L.; BUCK, J.W. The effect of fungicides on urediniospore germination and disease development of daylily rust. Crop Protection, Madison, v.22, p.135-140, 2003.

YANG, Z.; CHEN, H.; LI, Y.C. A new glycoside and a novel-type diterpene from Hemerocallis fulva (L.) L. Helvetica Chimica Acta, v.86, p.3305-3309, 2003.

ZHANG, Y.; CICHEWICZ1, R.H.; NAIR, M.G. Lipid peroxidation inhibitory compounds from daylily (Hemerocallis fulva) leaves. Life Sciences, v.75, p.753763, 2004. 